\section{Brickbats for fossil hunter who claims skull has false tooth}

\section{Rex Dalton}

Almost every important fossil hominid seems to spawn controversy. Now Toumai, man's oldest known ancestor, has his.

The integrity of the 7-million-yearold specimen (Sahelanthropus tchadensis) came under attack in April, when the South African Journal of Science published an article claiming that Toumaii's jaw had a molar glued in the wrong place to round out his set of teeth (A. Beauvilain and Y. Le Guellec $S$. Afr. J. Sci. 100, 142-145; 2004).

The article was written by Alain Beauvilain, a geographer from the University of Paris $\mathrm{X}$ and an author on the original paper, with Yves Le Guellec, a dentist acquaintance of his. Palaeoanthropologists say there is nothing wrong with the published description of Toumaï (M. Brunet et al. Nature 418, 145; 2002), which puts pressure on the South African journal to clarify matters.

The backlash against the pair, who attracted much attention in the French media when their article was published, began in June. Martin Pickford, chairman of palaeoanthropology and prehistory at the Collège de France in Paris and the reviewer of the article, wrote to the South African Journal of Science offering his "humble apologies" to the journal and to the leader of the Toumai discovery team, Michel Brunet, a palaeoanthropologist at the University of Poitiers. Pickford admits that he "paid insufficient attention" to details in the article.

Protests continued last month, when more than two dozen of the world's leading palaeoanthropologists wrote to the journal saying that the third molar on the right of Toumaii's jaw is indeed a right molar - not a left one as the critics claim. Brunet says his analysis shows that Toumaii's right molar matches breaks in the tooth's roots, apparently settling the argument.

Beauvilain has helped Brunet organize many trips to bandit-infested areas of the Sahara, but he acknowledges that he was not involved in writing the manuscript and is not a trained palaeoanthropologist.

The South African journal is trying to resolve the dispute, although it has not been able to contact Le Guellec, and Beauvilain is sticking to his guns. "The tooth is clearly from the left side, even if a number of palaeoanthropologists maintain it is from the right," he told Nature last week.

Additional reporting by Sabine Louët.

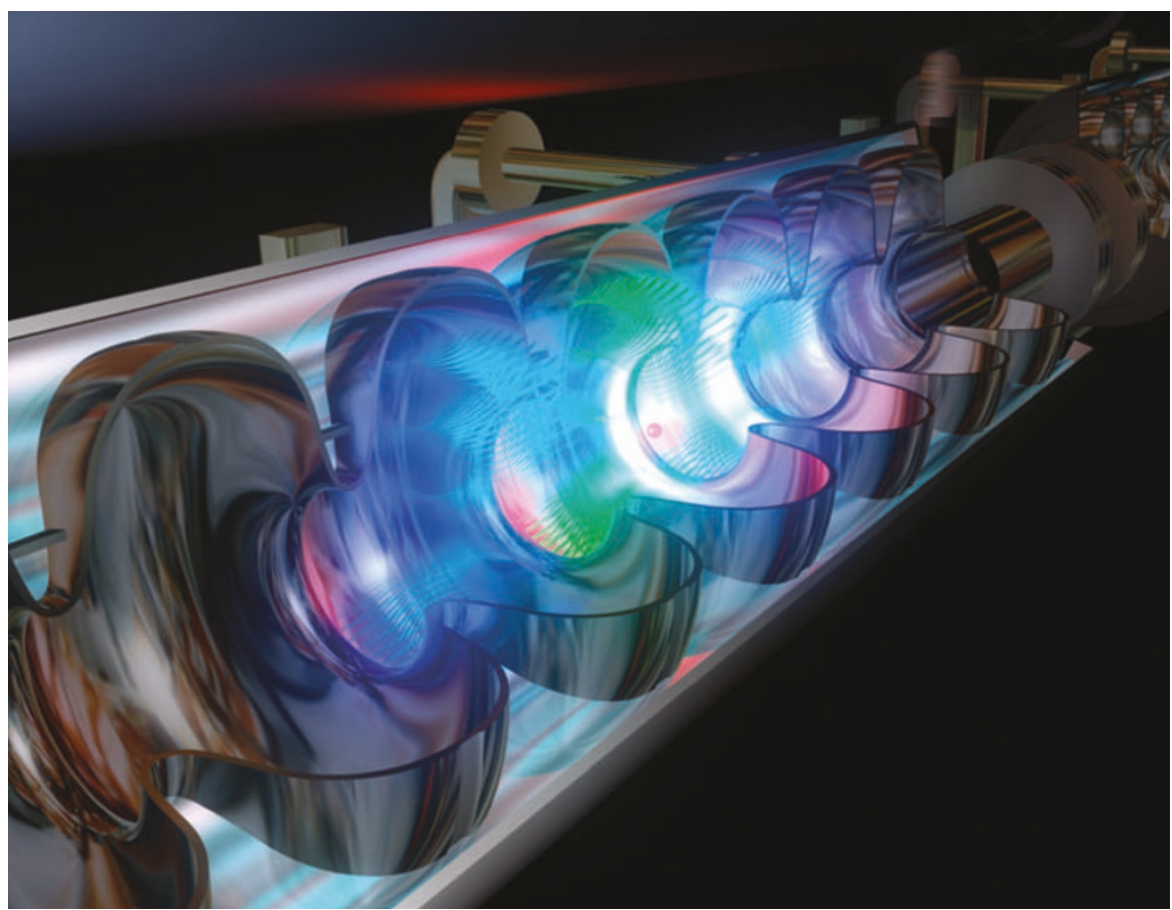

Along the right lines: Germany's niobium accelerator will lead research on the Higgs boson.

\title{
Superconductor beats copper in plans for particle collider
}

\section{Geoff Brumfiel and David Cyranoski}

Physicists have chosen the technology that will be used in the next generation of particle collider, an international experiment that hopes to study the particle thought to endow all others with mass.

The collider will use superconducting technology rather than copper coils, the International Committee for Future Accelerators decided on 20 August. The move, which comes after years of debate, means that hundreds of scientists in the United States and Japan, who have been working on the more traditional copper devices, must refocus their efforts.

Support for an international linear collider has been building over the past four years. The machine would smash together electrons and positrons, their antimatter equivalent, at enormous energies. This could generate the elusive Higgs boson, which theory predicts interacts with other subatomic particles to give them mass.

"You can think of the linear collider as a precision microscope," says Philip Burrows, a physicist at Queen Mary, University of London. "It is a tool that will allow us to really pin down the properties of the Higgs."

Two technologies have been front runners from the outset. Researchers at DESY, the German national research centre for particle physics in Hamburg, have promoted a design that uses superconducting niobium to create the huge electric fields for accelerating electrons and positrons (see Nature 410, 397;
2001). A rival system, which uses copper coils, was developed at KEK, the high-energy accelerator research organization in Tsukuba, Japan, and at the Stanford Linear Accelerator Center (SLAC) in California.

"This was a really difficult decision," says Barry Barish, head of the technical team charged with reviewing the two proposals. "Both technologies had their pluses and minuses." Copper coils, for example, are capable of accelerating the particles over a shorter distance, but the superconducting technology would use less energy. In the end, Barish says, the team settled on the superconducting technology for a variety of different reasons, including its ability to create beams with a higher density of particles, resulting in an increased collision rate.

The move is likely to help DESY, which has struggled in recent months to get funding from the German government for a smaller prototype machine. But it will also force researchers at SLAC and KEK, which until now have devoted millions of dollars to developing copper technologies, to change direction quickly. Still, the director of SLAC, Jonathan Dorfan, says: "Much of the progress will be able to be redirected."

With the technology chosen, Barish says, the international community will start designing the machine, and hope to deliver a preliminary blueprint by 2007. Although the cost of the machine is not yet known, Barish estimates that it will be "billions of dollars". 